\title{
Electromagnetic radiation of human body before and after intense exercise
}

\author{
R.S.S.A.Kadir, Zunairah Hj Murat, Nizaar Suhairy Bin Johari \\ Faculty of Electrical Engineering, Universiti Teknologi MARA (UiTM), Malaysia
}

\begin{tabular}{|c|c|}
\hline Article Info & ABSTRACT \\
\hline Article history: & This paper investigates the electromagnetic radiation (EMR) of the human \\
\hline Received Apr 8, 2019 & body before and after intense exercise. The intensity of exercise refers to the \\
\hline Revised Jul 9, 2019 & participated in this research. The data were collected at the specific point of \\
\hline Accepted Jul 28, 2019 & $\begin{array}{l}\text { the human body by using a frequency detector. The reading of the frequency } \\
\text { was taken } 5 \text { times at each point at the same location; hence, the average value }\end{array}$ \\
\hline Keywords: & $\begin{array}{l}\text { is calculated for data analysis. This frequency measurement is recorded two } \\
\text { times which is before and after intense exercise with a consistence protocol }\end{array}$ \\
\hline Electromaonetic radiation & for all participants. The collected data is analyzed by using MATLAB \\
\hline$(\mathrm{EMR})$ & programming tool which converts the data frequency into 15 colours of bio- \\
\hline Frequency detector & the health level of the samples at specific point. From the analysis, \\
\hline Intense exercise & $\begin{array}{l}\text { higher frequency of EMR is detected after intense exercise compared to } \\
\text { before intense exercise. There is also a significant change in the physical } \\
\text { health score categories. This indicates that the intense exercise influences the } \\
\text { body EMR radiation frequencies. }\end{array}$ \\
\hline
\end{tabular}

Copyright $\odot 2020$ Institute of Advanced Engineering and Science. All rights reserved.

\section{Corresponding Author:}

R.S.S.A.Kadir, Faculty of Electrical Engineering, Universiti Teknologi MARA (UiTM), 40450 Shah Alam, Selangor, Malaysia.

Email: ros885@salam.uitm.edu.my

\section{INTRODUCTION}

Exercise is the body activity that enhances or maintains physical fitness and overall health. Exercising is most perfect ways to maintain a person health, to stay fit, lose a body weight and boost up the mental capabilities [1]. Strength and balance exercise are the physical exercise specializing in the use of resistance to induce muscular contraction while the intense exercise is referred to how much energy is expended during exercising [2]. Every human body emits different Electromagnetic Radiation (EMR) depends on the activities of a person [3]. EMR consists of electromagnetic waves, which are synchronized oscillations of electric and magnetic fields that propagate at the speed of light through a vacuum [4].

Many people who have chronic medical condition resign themselves to lives of modest activity or zero activity at all, convinced that vigorous exercise is normally unsafe to their body [5]. From recent studies shows that high-intensity exercise may even better than regular aerobic activities for many patients with conditions like heart disease, diabetes, stroke and pulmonary disease [5]. Patient with the chronic pulmonary disease are unable to exercise long period to gain needed health benefits, therefore they can do high-intensity interval training (HIIT) for long period with less shortness of breath and leg discomfort [6]. Currently, there is no evidence to relate high-intensity exercise in the health condition of human through EMR, hence this study aimed to examine the EMR of the human body before and after intense exercise. 
A total of 30 sample involved in this research whereby all sample is undergoing the measurement of EMR. The data frequency is measured at 23 points around the body namely left side, right side and chakra points (refer Figure 1).
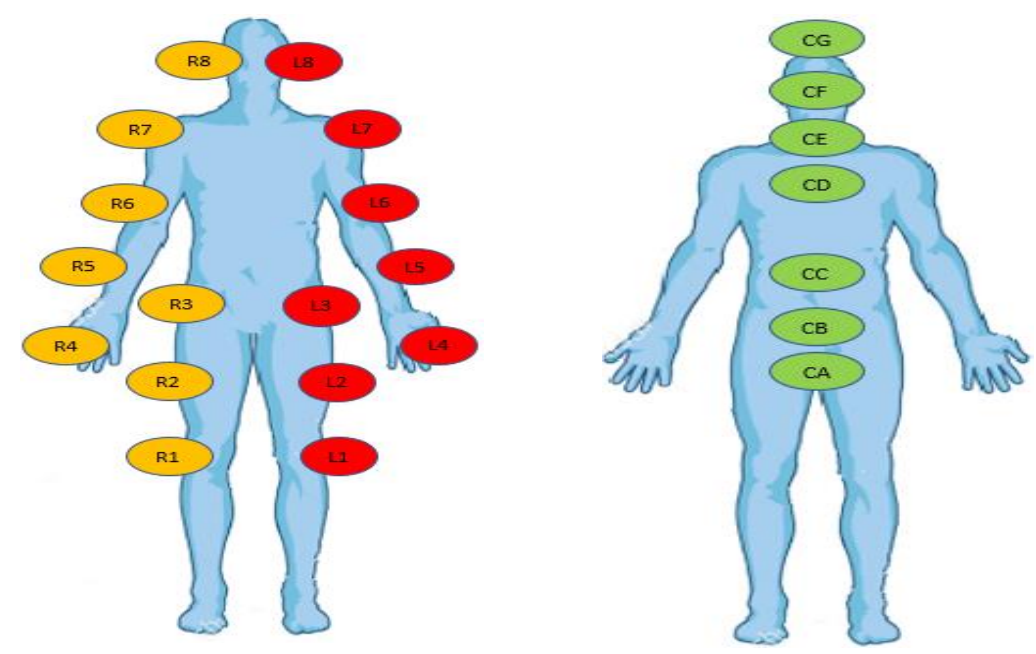

Figure 1. Point of measurement: left side, right side, and chakra points

\section{LITERATURE REVIEW}

\subsection{The Human Body EMR}

EMR is a type of energy propagated through free space or through a material medium in the form of electromagnetic waves. It has electric powered and magnetic areas that simultaneously oscillate in planes mutually perpendicular to one another and also to the path of propagation through space. Since the energies field has dynamic and enormous characteristics, this energies can be affected by any field of nearby object or organism [7]. Human beings also have been found to discharge radiation into the space surrounding their body. This radiation encircles the physical body and can be defined as endogenous energy fields produced by and contained within the body [8]. The previous study has stated that every living human body will emit a different frequency of EMR depending on their activities, lifestyle, and surrounding. The EMR also gives the information about human physical health [9-12].

\subsection{Intensity of Exercise}

Intensity exercise is the amount of power that expresses a maximum percentage of a human body during performing an activity [13]. The intensity exercise can be classified into 3 type level of intensity which is low intensity, moderate intensity and high intensity [14]. Table 1 below shows low, moderate and high levels of exercise intensity can be measure through the increase of the heart rate per minute. The higher intensity of the activity being performed, the higher the heart rate [15-18]. In this research will be a focus on the high-intensity interval training activity toward the electromagnetic radiation that will emit from the human body. High-intensity interval training (HIIT) can be categorized by repeated sessions of exercise that performed with an "all out" effort [17]. The intense exercise periods may range from 5 seconds to 8 minutes long and are performed at $80 \%$ to $95 \%$ of a person estimated maximal heart rate [17]. Intense efforts are usually performed against a heavy resistance in order to increase skeletal muscle mass, HIIT is normally connected with activities such as cycling or running [14]. HIIT has been proven to reduce subcutaneous fat significantly, abdominalafat especially [19]. HIIT also burns more calories and increases post-exercise fat oxidation and energy expenditure more than steady-state exercise.

Table 1. Measurement of the Level of Intensity on the Human Body by

\begin{tabular}{cc}
\multicolumn{2}{c}{ Calculating the Heart Rate per Minute [14] } \\
\hline Level of Intensity & Heart Rate Per Minute \\
\hline Low & 68 -to-92 beats per minute \\
Moderate & 93 -to-118 beats per minute \\
High & more than 119 beats per minute \\
\hline
\end{tabular}




\subsection{Frequency Detector}

The frequency detector as demonstrated in Figure 2 is an experimental electromagnetic feedback and imaging process. Frequency detector does give comprehensive information regarding a patient's health conditions and provides a technical and detailed level of information. The frequency detector system identifies and interprets 15 colours of bioenergy accurately, representing all 15 distinguishable colours of the optical spectrum. The frequency detector is an experimental electromagnetic measurement and imaging process which is the first imaging technology that creates full-color bioenergy charts such as objects, plants, and animals [20].

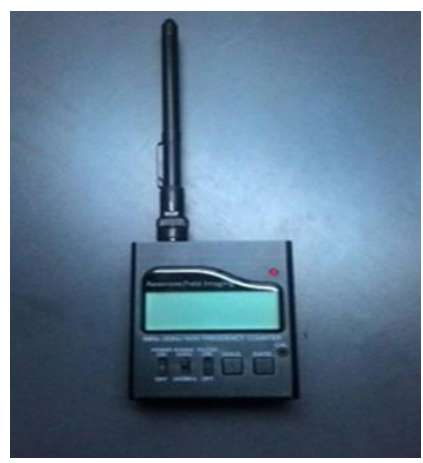

Figure 2. Frequency detector

\section{RESEARCH METHOD}

\subsection{Data Collection}

The research is performed at the Stadium University Technology MARA (UiTM). The data was collected during evening time which is at $5.00 \mathrm{pm}$ until $6.30 \mathrm{pm}$ [21]. Based on the previous study, the human body is at the best performance during evening time compared to during morning at suitable ambient temperature [22-24]. This is the time of day when the body is in peak condition for physical activity. Intense exercise in this research is fixed, whereby the volunteer need to run 100 meters in 1 minutes. Before starting the data collection, the heart rate of the sample is a measure to ensure the student body is in the steady-stated. The frequency detector is placed to the specific points of the human body and the gap must be $2-5 \mathrm{~cm}$ from the selected point so that the data can be more accurate [3]. The human EMR is collected 5 times at each points and hence the average of frequency will be calculated for further analysis. This data are transfer into a software which is to convert from frequency into bioenergy colour aura.

\subsection{Data Acquisition and Data Analysis}

For the EMR analysis, the data is analyzed at 16 points of measurement both sides of the body. Meanwhile, for chakra analysis, all 7 points are being analyzed. Volunteer students are advised to wear a sportswear and away from electronic devices during data acquisition in order to maintain the accuracy of the measurement. Microsoft Excel is used in data analysis. Meanwhile, Table 2 shows the physical health score and Table 3 shows the range of total score which determines the categories of a person health in this research.

Table 2. Physical Health Score

\begin{tabular}{cc}
\hline Range of total score & Category \\
\hline$>75$ & Excellent \\
$56-75$ & Good \\
$31-55$ & Moderate \\
$15-30$ & Poor \\
\hline
\end{tabular}

Table 3. The Range of Total Score

\begin{tabular}{ccc}
\hline Category & Color & Score \\
\hline Excellent & Gold, Silver & 5 \\
Good & White, Orchird, Cyan & 4 \\
Moderate & Rose, Purple, Blue & 3 \\
& Navy, Green, Yellow, Orange, Black & 2 \\
Poor & Burgundy & 1 \\
& Red & 0 \\
\hline
\end{tabular}

\section{RESULTS AND ANALYSIS}

30 students participated in this research on the left and right side of the human body while for chakra analysis only 10 students are involved. In the first analysis before and after intense exercise, the graph has been plotted to examine the variability of EMR on the sample as shown in the Figure 3 - Figure 5 for the left side, right side, and chakra. 


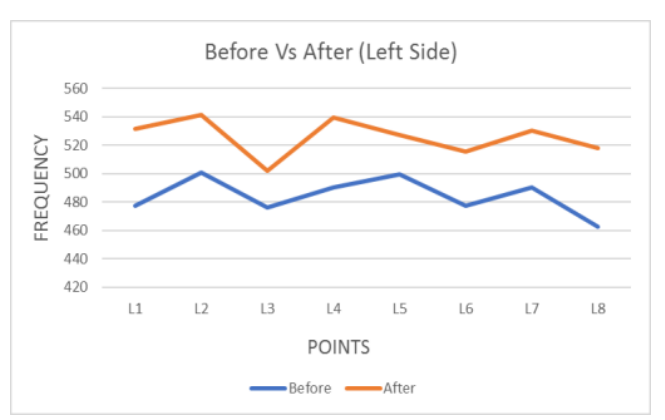

Figure 3. The average frequency before vs after (left side)

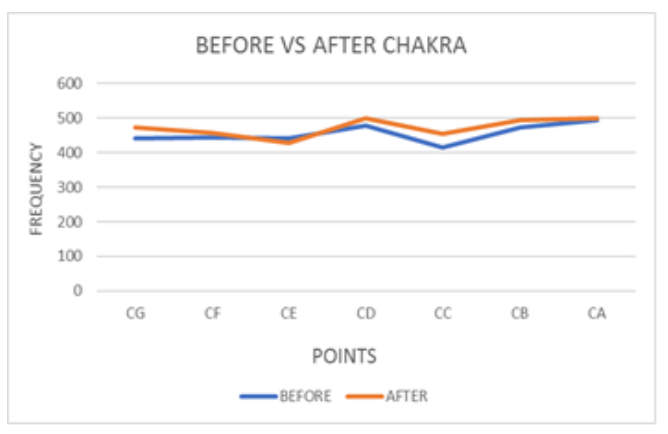

Figure 5. The average frequency before vs after (chakra)

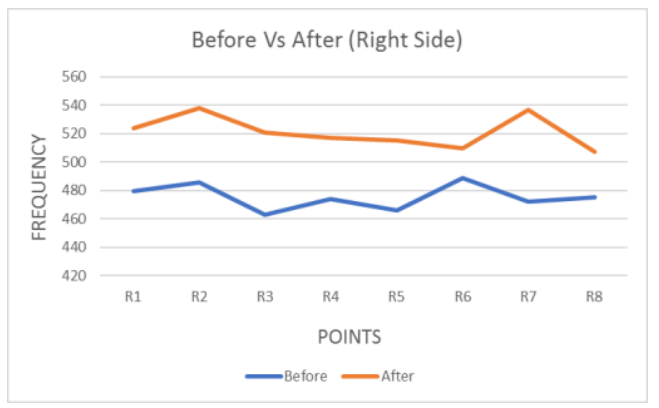

Figure 4. The average frequency before vs after (right side)

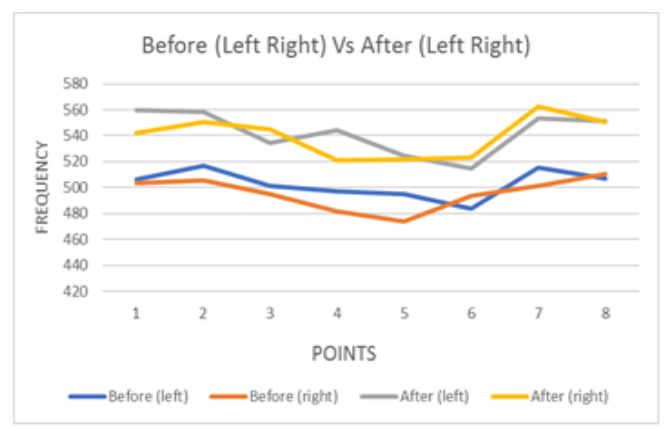

Figure 6 . The average frequency before (left right) vs after (left right)

\subsection{Frequency Analysis}

From the observation of Figure 3 - Figure 5, both sides of the human body showed that the EMR frequency before intense exercise is slightly lower than after intense exercise frequency while on the chakra part of the EMR frequency are almost the same for both, before and after intense exercise. Secondly, the comparison between before (left-right) and after (left-right) are been examined as shown in Figure 6. Form visual inspection, the average frequency reading on both left and right side of the human body after intense exercise are higher as compared to before intense exercise.

\subsection{Analysis Using Colour Interpretation for Physical Condition}

In this analysis the EMR on the left side, right side and chakra are converted into 15 colour spectrum (Resonant Field Imaging: Innovation Technologies and Energy Medicine, 2009). From the colour interpretation, it will determine and identify the physical health score of 23 points based on Table 3.

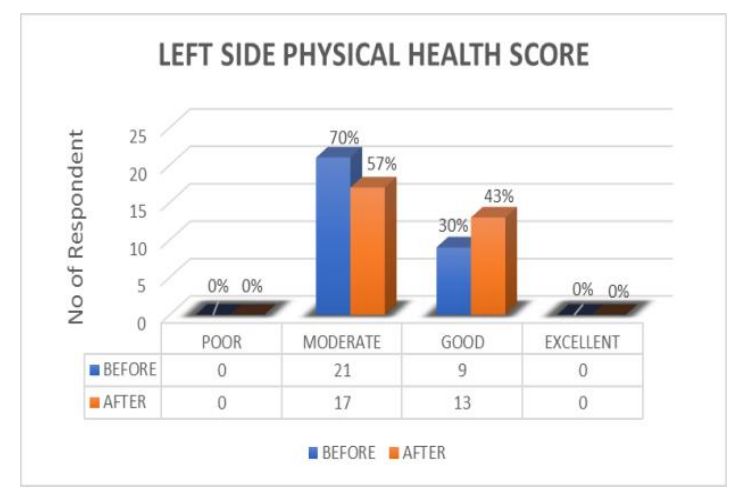

Figure 7. Number of respondent for left side physical health score

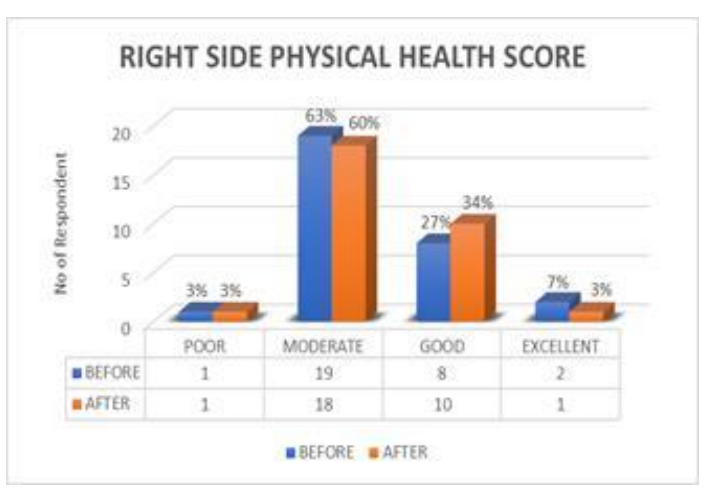

Figure 8. Number of respondents for right side physical health score 


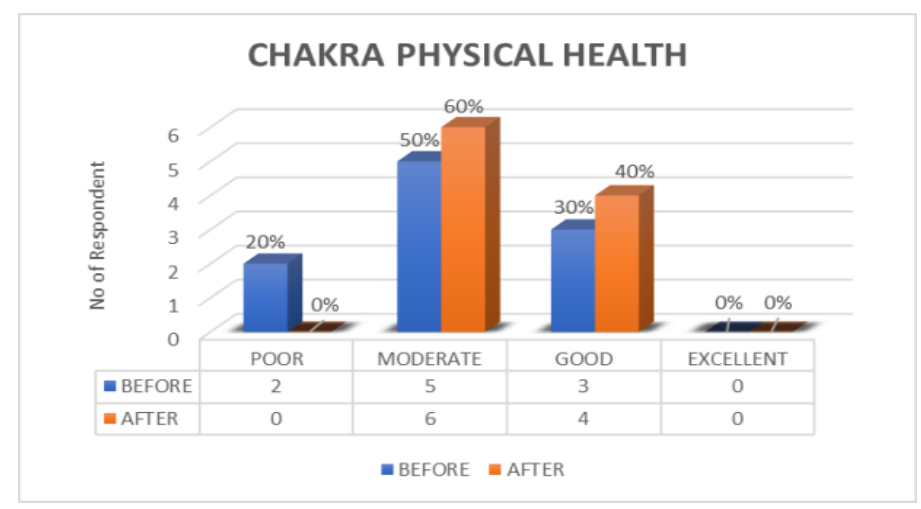

Figure 9. Number of respondents for chakra physical health

Based on Figure 7, there is $0 \%$ number of respondent are in poor categories for both conditions before and after intense exercise. Beside that, on the moderate categories there is $70 \%$ number of the respondent before intense exercise while $57 \%$ after doing intense exercise. Next, the number of respondent before intense exercise in good categories shows that $30 \%$ while for after intense exercise is $43 \%$. From the review of the graph, the number of respondent decrease after doing intense exercise in moderate categories while the number of respondent in the good categories increase after doing intense exercise. This shows that the intense exercise in this research gives a good impact toward the left side of the human body.

Figure 8 shows that the number of respondent on the poor categories has $3 \%$ for both conditions before and after intense exercise. In the moderate categories, it shows that percentage the number of respondents is slightly decreased from $63 \%$ to $60 \%$ after doing intense exercise. Meanwhile, in the good categories it shows that the percentage number of respondent increase from $27 \%$ to $34 \%$ after doing intense exercise. However, in the excellent categories the number of respondent before intense exercise has $7 \%$ while after intense exercise is $3 \%$. The significant changes in the number of the respondent have proven that the intense exercise gives a good impact toward the right side of the human body. Figure 9 shows that the number of the respondent before intense exercise has $20 \%$ in poor categories as compared to after intense exercise has $0 \%$. However, in the moderate categories the number of respondents before intense exercise has $50 \%$ while after intense exercise is $60 \%$. Lastly, for the good categories there is $30 \%$ number of respondents before intense exercise and after intense exercise has $40 \%$.

\section{CONCLUSION}

In conclusion, the EMR before and after intense exercise presented in this research indicated that the data have different types of pattern. From the analysis, higher frequency of EMR is detected after intense exercise compared to before intense exercise. The result also shows that the number of respondents increasing from the moderate categories into good categories. This means the intense of exercise gives a good impact toward the human body, means the intense exercise also give significant change in the physical health score categories of the sample which indicates that the intense exercise influences the body EMR radiation frequencies. This finding is inline with previous study [25].

\section{ACKNOWLEDGEMENTS}

The authors would like to express the deepest gratitude to University Teknologi MARA (UiTM) in providing the Lestari Fund (RMI File Number: 600-IRMI/DANA 5/3/LESTARI (0025/2016)) research grant. The authors also want to show appreciation toward Faculty of Electrical Engineering UiTM for giving opportunity to complete this research. Thanks also to staffs from Biomedical Research and Development Laboratory for Human Potential who showed their support throughout this research. Special thanks goes to all sample who participated in this research.

\section{REFERENCES}

[1] S. Davis, "Healthy Mind, Healthy Body: Benefits of Exercise," The Joseph B. Martin Conference Center Harvard Medical School, 2014.

[2] L. Clemson, Strength and Balance Exercise Manual (no. 3rd North American edition). 
[3] Z. H. M. R.S.S.A. Kadir, M.N. Taib, " Preliminary study of human body electromagnetic radiation for stroke patients," Faculty of Electrical Engineering, pp. 140 - 144, 2015.

[4] (April 2014). Electromagnetic radiation. Available: https://en.wikipedia.org/wiki/Electromagnetic_radiation

[5] S. Physical Fitness. (2016). Understanding High Intensity Interval Training (HIIT). Available: https://familysporthealth.com/understanding-high-intensity-interval-training-hiit/

[6] M. J. Gibala, "<HighIntensityTraining.pdf>," vol. 20, p. 105, 2007.

[7] Rubik, B, Measurement of The Human Bio-field and Other Energetic Instruments. Foundation for Alternative and Integrative Medicine. 2009

[8] Liboff, A. R, Toward an Electromagnetic Paradigm for Biology and Medicine. Journal of Alternative and Complementary Medicine, 10, 41-47. 2004

[9] R. S. S. A. K. Mastura Rosdi, Zunairah Hj Murat and Nadiah Kamaruzaman, " The comparison of human body Electromagnetic radiation between Down Syndrome and Non Down Syndrome person for brain, chakra and energy field stability score analysis," Faculty of Electrical Engineering, pp. Pages: 370 - 375, 2012.

[10] R. S. Sheikh Abdul Kadir, Z. H. Murat, H. Hashim and W. N. Wan Muhammad, "A Preliminary Study on Human Body Aura of Smoker and Non Smoker using Resonant Field Imaging (RFI)," IEEE International Conference on System Engineering and Technology (ICSET) 2011.

[11] H. Abdul Rahman, S. N. Mohamad Rameli, R. S. Abd Kadir, Z. H. Murat and M. N. Taib, "Analysis of Correlation Between Body Mass Index and Human Physical Condition using Resonant Field Imaging System (RFI)," RF and Microwave Conference 2008, December 2008.

[12] Prakash, S., Chowdhury, A. R., \& Gupta, A, Monitoring the human health by measuring the biofield" aura": An overview. Int J Appl Eng Res, 10(2765427658), 2015.

[13] Laursen, Paul B," Training for intense exercise performance: high-intensity or high-volume training?", Scandinavian journal of medicine \& science in sports, Vol 20, 1-10, 20102010

[14] T. W. W. R. Department. Exercise Intensity Levels. Available: http://www.weightwatchers.com/util/art/index_art.aspx?tabnum=1\&art_id=20971

[15] Mai, Katsuji, et.all, "Vagally mediated heart rate recovery after exercise is accelerated in athletes but blunted in patients with chronic heart failure", Journal of the American College of Cardiology, Vol. 24, Issue 6, 1529-1535, 1994.

[16] Moser, Othmar et all, "Different heart rate patterns during cardio-pulmonary exercise (CPX) testing in individuals with type 1 diabetes", Frontiers in endocrinology, vol. 9, 585, 2018.

[17] P. Martin J. Gibala, "High-Intensity Interval Training: New Insights," vol. 20, p. 105, 2007.

[18] Le Meur, Y., Buchheit, M., Aubry, A., Coutts, A. J., \& Hausswirth, C, Assessing overreaching with heart-rate recovery: what is the minimal exercise intensity required?. International journal of sports physiology and performance, 12(4), 569-573, 2017.

[19] L. Kravitz, "High-Intensity Interval Training," in Internet, A. C. o. S. Medicine, Ed., ed, 2014.

[20] Resonant Field Imaging: Innovation Technologies and Energy Medicine. 2009.

[21] Z. H. Murat, M. N. Taib, S. Lias, R. S. S. A. Kadir, N. Sulaiman, and M. Mustafa, "EEG analysis for brainwave balancing index (BBI)," in Computational Intelligence, Communication Systems and Networks

[22] A. S. Jafarzadeh Gholamhasan, Rastegari Ghiri Mehdi a 123 nd 4Mirghani Seyed Javad, "The Effect of Exercise in the Morning and the Evening Times on Aerobic and Anaerobic Power of the Inactive Subjects," World Applied Sciences Journal, 2013.

[23] Kadir, R. S. S. A., Murat, Z. H., \& Suhaimi, N. I. N. B. M, Electromagnetic Radiation (EMR) of Human Body Before and After Jogging. Indonesian Journal of Electrical Engineering and Computer Science, 9(3), 643-649, 2018.

[24] W. H. bin Mohd Saad, K. C. Wuen, M. bin Mat Ibrahim, N. H. B. M. Saad, S. B. A. Radz, A. S. bin Mohamad Shokri, et al., "Study on the Effect of the Ambient Temperature toward the Quality of Sleep," International Journal of Electrical and Computer Engineering (IJECE), vol. 7, pp. 2986-2992, 2017.

[25] I. S. D. a. Z. A. Myecheia Minter Jordan, "Healthy Mind, Healthy Body: Benefits of Exercise," presented at the Longwood Seminars, 2014

\section{BIOGRAPHIES OF AUTHORS}

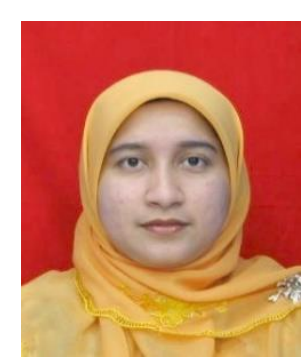

Ros Shilawani Bt. S. Abdul Kadir obtained Bachelor of Science in Electrical and Electronic Engineering (Hons.) in 2000 from Universiti Tenaga Nasional, Selangor, MSc in Personal, Mobile and Satellite Communication (2003) from University of Bradford, United Kingdom, PhD in Electrical and Electronic Engineering from Universiti Teknologi MARA. Her research interest mainly concerns on bio-medical engineering which involve the development of human potential. She is currently working as senior lecturer in UiTM Shah Alam. She used to work as Data Network Engineer in DiGi Telecommunication Sdn. Bhd. 


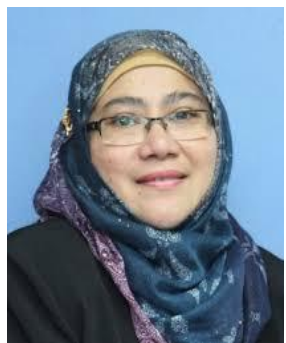

Centre for Studies Centre for System Engineering Studies Academic Qualification

MSc Electrical Engineering Syracuse University USA 1991

BSc Electrical Engineering Syracuse University USA 1989

Research Area: Biomedical Engineering. Brainwave. EEG. Human body Radiation. Human Potential.

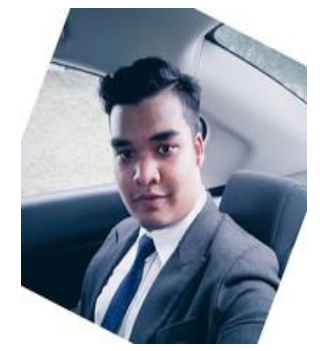

\section{Academic Qualification}

BSc Electrical and Electronic Engineering Universiti Teknologi MARA 2019

Research Area: Biomedical Engineering, Human body Radiation, Human Potential. 